\title{
A Reovirus Causes Hypovirulence of Rosellinia necatrix
}

\author{
S. Kanematsu, M. Arakawa, Y. Oikawa, M. Onoue, H. Osaki, H. Nakamura, K. Ikeda, \\ Y. Kuga-Uetake, H. Nitta, A. Sasaki, K. Suzaki, K. Yoshida, and N. Matsumoto
}

First, third, fourth, tenth, eleventh, and twelfth authors: Department of Apple Research, National Institute of Fruit Tree Science, 92 Nabeyashiki, Shimokuriyagawa, Morioka 020-0123, Japan; second, sixth, seventh, eighth, and thirteenth authors: National Institute of Agro-Environmental Science, Tsukuba 305-8604, Japan; fifth author: National Institute of Fruit Tree Science, Tsukuba 305-8605, Japan; and ninth author: Hiroshima Agricultural Research Center, Akitsu 729-2402, Japan.

Current address of M. Arakawa: Faculty of Agriculture, Meijo University, Shiogamaguchi, Tenpaku, Nagoya 468-8502 Japan.

Current address of H. Nakamura, A. Sasaki, and K. Yoshida: National Institute of Fruit Tree Science, Tsukuba 305-8605, Japan.

Current address of K. Ikeda: National Institute of Agrobiological Sciences, Tsukuba 305-8602, Japan.

Current address of Y. Kuga-Uetake: Faculty of Agriculture, Shinshu University, 399-4598, Japan.

Accepted for publication 16 January 2004.

\begin{abstract}
Kanematsu, S., Arakawa, M., Oikawa, Y., Onoue, M., Osaki, H., Nakamura, H., Ikeda, K., Kuga-Uetake, Y., Nitta, H., Sasaki, A., Suzaki, K., Yoshida, K., and Matsumoto, N. 2004. A reovirus causes hypovirulence of Rosellinia necatrix. Phytopathology 94:561-568.

White root rot, caused by Rosellinia necatrix, is a serious soilborne disease of fruit trees and other woody plants. R. necatrix isolate W370 contains 12 segments of double-stranded RNA (dsRNA) that is believed to represent a possible member of the family Reoviridae. W370 was weakly virulent and its hyphal-tip strains became dsRNA free and

W370dsRNA-transmitted strains were less virulent than their parent strain RT37-1 on apple seedlings, with mortality ranging between 0 to $16.7 \%$ in apple seedlings that were inoculated with the W370dsRNA-containing strains and 50 to $100 \%$ for seedlings inoculated with the dsRNA-free strains. Some W370dsRNA-containing strains killed greater than $16.7 \%$ of seedlings, but these were found to have lost the dsRNA in planta. These results indicate that W370dsRNA is a hypovirulence factor in $R$. necatrix. In addition, a strain lost one segment (S8) of W370dsRNA during subculture, and the S8-deficient mutant strain also exhibits hypovirulence in $R$. necatrix.
\end{abstract} strongly virulent. The 12 segments of W370dsRNA were transmitted to hygromycin B-resistant strain RT37-1, derived from a dsRNA-free strain of W370 in all or none fashion through hyphal contact with W370. The
Additional keyword: transformation.
Rosellinia necatrix Prill. is a soilborne ascomycetous fungus that causes white root rot on a wide range of plant species, especially on fruit trees such as apple, grape, and Japanese pear $(6,20,40)$. This fungus invades from lateral roots, causing decline of trees. Once lesions girdle the trunk base, the infected tree is finally killed. The current control method for the disease in Japanese orchards involves drenching the soil around individual trees with 50 to 200 liters of the fungicide fluazinam (18). Though chemical control is effective, a novel management method carrying fewer environmental risks has been sought.

The use of double-stranded RNA (dsRNA) for attenuating virulence of $R$. necatrix is considered feasible in this context (24). Fruit trees are highly profitable on a per plant basis, and biological control with a fungal virus that reduces virulence should be beneficial. Moreover, fungal viruses do not induce environmental pollution because they infect through cytoplasmic contact of the host fungus. Many fungal viruses have dsRNA as genomes and, although most of the dsRNAs do not have an overt effect on their hosts, some of them are known to be hypovirulence factors and reduce the virulence of the fungal host $(8,15)$.

In a survey of $R$. necatrix isolates from all over Japan for the presence of dsRNA, we detected dsRNAs in 65 (21.8\%) out of 298 isolates collected (5). Forty-five distinct dsRNA profiles were identified by polyacrylamide gel electrophoresis (PAGE); each consisted of 1 to 12 bands, which ranged from less than 1,000 bp

Corresponding author: S. Kanematsu; E-mail address: satokok@affrc.go.jp

Publication no. P-2004-0405-01R

(C) 2004 The American Phytopathological Society to more than $10 \mathrm{kbp}$ in size (5). In subsequent inoculation tests to estimate virulence, a set of dsRNAs with multiple segments was identified in isolate W370 (W370dsRNA) as a potential hypovirulence factor. The W370dsRNA is considered to be a member of fungal family Reoviridae because the dsRNA consisted of 12 segments, with molecular weight ranging from $\approx 0.41$ to $2.95 \times$ $10^{6}$, and it has conserved terminal sequence at both $5^{\prime}$ and $3^{\prime}$ ends (33). Moreover, double-shelled spherical particles approximately $80 \mathrm{~nm}$ in diameter associated with W370dsRNA were observed (43). The nucleotide sequences of the 10 genome segments reported by Osaki et al. (33) and Wei et al. (43) encode a unique, long open reading frame on each segment, as in the case with other members of Reoviridae. The deduced amino acid sequences of W370dsRNA segment 2, 4, 6, and 12 show partial similarities to proteins of viruses in the family Reoviridae (i.e., methyltransferase, a cell-binding protein, a core protein that has NTP-binding function, and a core capsid protein precursor, respectively). Analysis on the putative proteins encoded on the other six segments using the protein database programs BLAST, Motif, and Pfam revealed no clear similarity to any known proteins. A dsRNA molecule with 11 segments was detected from the hypovirulent isolate C-18 of Cryphonectria parasitica (13). The properties of C-18 dsRNA also are reminiscent of the family Reoviridae of dsRNA viruses (13), though the relationship between the dsRNAs in W370 and C-18 is unclear because genome sequence of the latter has not been reported. Reoviruses hitherto have been found in invertebrate, vertebrate, and plant hosts, but not in fungal hosts (42). Therefore, W370dsRNA and C18dsRNA also are interesting in virus classification, not only from a practical viewpoint. 
Here, we demonstrate hypovirulence of the W370dsRNA in $R$. necatrix by curing and transmission tests. In our preliminary study, transmission of W370dsRNA was restricted to the proximity along the colony junction in paired cultures; therefore, we established a transformation procedure of $R$. necatrix to obtain antibiotic-resistant transformants for critical examination of dsRNA transmission.

\section{MATERIALS AND METHODS}

Fungal isolates and transformation vector. $R$. necatrix isolate W370 was obtained from a root of Japanese pear in Yamato, Hiroshima and contains 12 segments of dsRNA $(5,33,43)$ (Fig. 1A). Hyphal tip cultures were done with isolate W370 to remove dsRNA. W370 T1 is a representative hyphal-tipped culture confirmed by PAGE (Fig. 1A) and reverse-transcription polymerase chain reaction (RT-PCR) (Fig. 2) to be dsRNA free. Isolates W37, W97, and W718 were obtained from roots of Japanese pear in Ichikawa, Chiba, Inzei, Chiba, and Imari, Saga, respectively. These isolates were determined to be vegetatively incompatible with W370 and its hyphal tip strains by the presence of a dark demarcation line between colonies in paired culture. All the isolates and strains were cultured on potato dextrose agar (PDA; Difco Laboratories, Detroit) and stored at $5^{\circ} \mathrm{C}$. Plasmids pSH75 (22) and pAN7.1 (35) contained the bacterial hygromycin B phosphotransferase gene under the control of the promoter and terminator of the Aspergillus nidulans trpC gene and glyceraldehyde-3-phosphate dehydrogenase gene, respectively.

Hyphal tip isolation. Fungal cultures were grown on 1.5 or $2.5 \%$ water agar (WA) plates in the dark at $25^{\circ} \mathrm{C}$ for 7 to 14 days. Hyphal tips containing two to eight cells were removed from the colony margin under a dissecting microscope and transferred onto a piece of cellulose membrane $(3 \times 3 \mathrm{~cm})$ on a 5.5 -cm-diameter PDA plate and grown at $25^{\circ} \mathrm{C}$ for 5 to 7 days or at $20^{\circ} \mathrm{C}$ for 10 days. Following incubation, the mycelia were removed with the cellulose membrane for dsRNA extraction. Mycelial growth beyond the membrane was transferred to PDA slants and stored at $5^{\circ} \mathrm{C}$.
Protoplast production. Five 6-mm-diameter mycelial plugs from PDA cultures were transferred to four replicate 200-ml Erlenmeyer flasks containing $30 \mathrm{ml}$ of potato dextrose broth (PDB; Difco Laboratories) and incubated in the dark at $25^{\circ} \mathrm{C}$ without shaking for 7 days. Mycelia were harvested by centrifuging the cultures at $5,000 \times g$ for $15 \mathrm{~min}$, then homogenized in $120 \mathrm{ml}$ of fresh PDB using a Waring blender at 7,000 rpm for $30 \mathrm{~s}$. Aliquots of $10 \mathrm{ml}$ of mycelial suspension then were added to 12 replicate 200-ml Erlenmeyer flasks containing $30 \mathrm{ml}$ of new PDB. The 12 flasks containing $40 \mathrm{ml}$ of culture were incubated statically for 2 days at $25^{\circ} \mathrm{C}$ in the dark. Young mycelia were harvested by centrifugation at $5,000 \times g$ for $15 \mathrm{~min}$ and washed once with osmoticum (0.6 M mannitol, $10 \mathrm{mM}$ 3-morpholinopropanesulfonic acid [MOPS], $\mathrm{pH}$ 7.0) by centrifugation. They were resuspended gently in filter-sterilized enzyme-osmoticum mixture containing 0.4\% Zymolyase 100T (Seikagaku Co., Tokyo) and 1\% Lysing Enzymes (Sigma-Aldrich, St. Louis) and incubated at $20^{\circ} \mathrm{C}$ for $2 \mathrm{~h}$ with gentle shaking. The cultures were filtered through two layers of gauze, and then thorough a stainless steel mesh with $45-\mu \mathrm{m}$ openings to remove debris. Protoplasts were collected by centrifugation at $3,000 \times g$ for $10 \mathrm{~min}$, washed twice with osmoticum by centrifugation, and suspended in $250 \mu \mathrm{l}$ of MMC buffer (0.6 M mannitol, $10 \mathrm{mM}$ MOPS, $\mathrm{pH}$ 7.0, and $10 \mathrm{mM} \mathrm{CaCl}_{2}$ ). The protoplast suspension was kept on ice and final concentrations determined with a hemacytometer.

Transformation. Protoplast suspension $(100 \mu \mathrm{l} ; \approx 0.5$ to $1 \times$ $10^{7}$ protoplasts $/ \mathrm{ml}$ ) and $10 \mu \mathrm{g}$ of vector plasmid were dispensed in a Falcon 2059 tube (Becton Dickinson, Franklin Lakes, NJ), mixed gently, and placed on ice for $30 \mathrm{~min}$. Following the addition of $500 \mu \mathrm{l}$ of PEG solution $(60 \%$ polyethylene glycol [PEG 4000], average molecular weight [MW] 3,000 [Wako, Osaka, Japan], $10 \mathrm{mM}$ MOPS, $\mathrm{pH} 7.0$, and $10 \mathrm{mM} \mathrm{CaCl}_{2}$ ), the protoplast suspension was gently mixed and incubated at $20^{\circ} \mathrm{C}$ for $20 \mathrm{~min}$. Each tube received $700 \mu$ of regeneration broth (PDB amended with $0.5 \mathrm{M}$ glucose) and was incubated statically in the dark at $25^{\circ} \mathrm{C}$ for 7 days. Aliquots containing $300 \mu \mathrm{l}$ of protoplasts were plated to $10 \mathrm{ml}$ of YCDA $(0.1 \%$ yeast extract, $0.1 \%$ casein hydrolysate [enzymatic], $0.5 \mathrm{M}$ glucose, and $1.5 \%$ agar in a $9-\mathrm{cm}-$
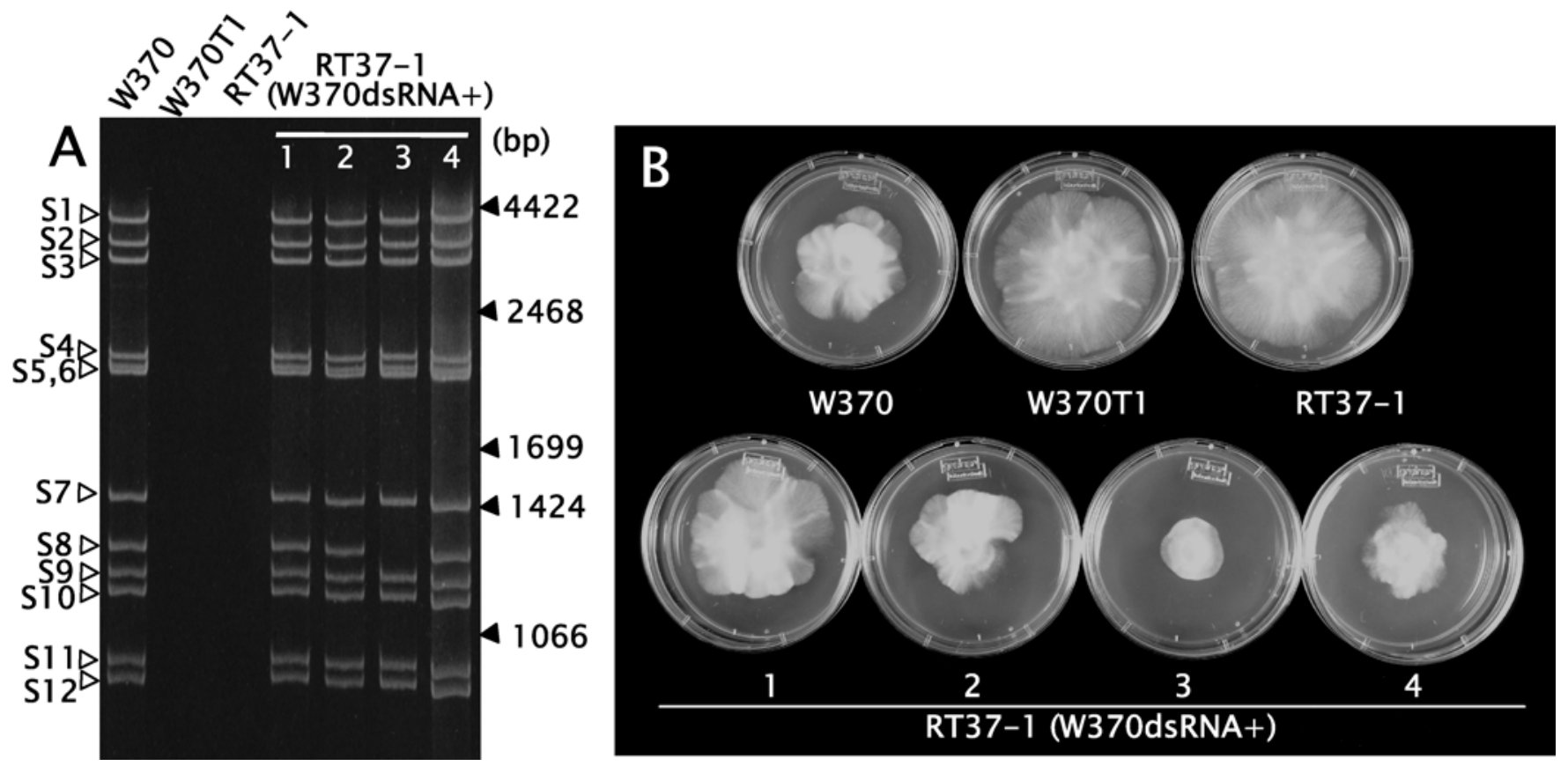

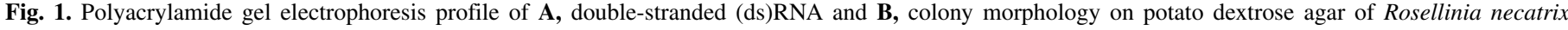

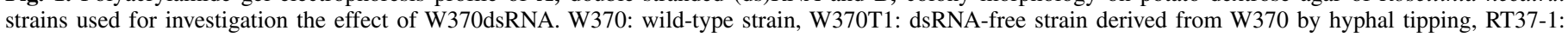

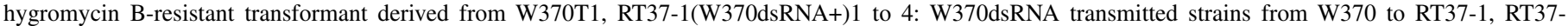

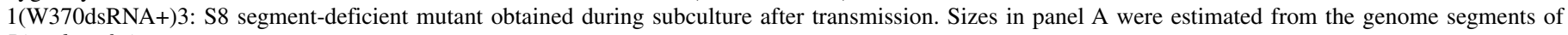
Rice dwarf virus. 
diameter petri dish) and incubated at $25^{\circ} \mathrm{C}$ in the dark. Mycelia regenerated in $\approx 3$ to 4 days, and plates were overlaid with $10 \mathrm{ml}$ of PDA containing hygromycin B (Roche, Mannheim, Germany) at $80 \mu \mathrm{g} / \mathrm{ml}$. Hygromycin B-resistant colonies that emerged on the surface of the plate were transferred to PDA containing hygromycin B at $50 \mu \mathrm{g} / \mathrm{ml}$. They were screened again on PDA containing hygromycin B at $100 \mu \mathrm{g} / \mathrm{ml}$ to establish transformants. Transformation was confirmed by PCR or Southern hybridization by the following procedure. Total DNA was extracted from fungal strains according to the method of Choi et al. (10). PCR analysis was performed with the primer pair $h p h 1$ (5'-CGTGATTTCATATGCGCGAT) and $h p h 4$ (5'-CTACTCTATTCCTTTGCCCTCG) that was constructed on the basis of $h p h$ gene sequence. PCR was conducted in $25 \mu \mathrm{l}$ of mixture containing $1 \mu \mathrm{l}$ of DNA (estimated to be approximately $50 \mathrm{ng}$ ), $0.4 \mu \mathrm{M}$ each of primer $h p h 1$ and hph4, $10 \mathrm{mM}$ Tris-HCl, $\mathrm{pH} 8.3,50 \mathrm{mM} \mathrm{KCl}, 2.5 \mathrm{mM} \mathrm{MgCl}_{2}$, $0.2 \mathrm{mM}$ each dNTP, and 0.625 units of AmpliTaq gold (Applied Biosystems, Foster City, CA). PCR amplification parameters were as follows: one step at $95^{\circ} \mathrm{C}$ for $10 \mathrm{~min}$, followed by 35 cycles at $94^{\circ} \mathrm{C}$ for $1 \mathrm{~min}, 56^{\circ} \mathrm{C}$ for $30 \mathrm{~s}$, and $72^{\circ} \mathrm{C}$ for $30 \mathrm{~s}$. PCR amplification products were analyzed by agarose gel electrophoresis. For Southern hybridization, $10 \mu \mathrm{g}$ of fungal DNA was digested with SalI, electrophoresed in $0.8 \%$ agarose gel, and blotted to Hybond $\mathrm{N}^{+}$membrane (Amersham Pharmacia Biotech, Buckinghamshire, UK) following standard methods (38). The $h p h$ gene fragment was hybridized with digoxigenin (DIG)-labeled PCR probes synthesized with the aid of the PCR DIG labeling kit (Roche Diagnostics, Mannheim, Germany) instead of dNTP using the amplification parameters described above. Hybridization was carried out in DIG Easy hyb granules (Roche Diagnostics) at $40^{\circ} \mathrm{C}$. The membrane was washed under a high stringency condition, and chemiluminescent signals were detected with the aid of CDP-star (Roche Diagnostics) according to the DIG systems protocol.

Extraction of dsRNA. Extraction and detection of total RNA from cellophane-grown cultures followed the procedure of Choi et al. (10) with minor modifications. Cellophane-grown cultures $(3 \times 3 \mathrm{~cm})$ were ground to a fine powder in liquid nitrogen with a mortar and pestle. The powder was suspended in $700 \mu \mathrm{l}$ of extraction buffer $(150 \mathrm{mM}$ sodium-acetate, $\mathrm{pH} 5.0,100 \mathrm{mM} \mathrm{LiCl}$, $4 \%$ sodium dodecyl sulfate, $10 \mathrm{mM}$ EDTA, $\mathrm{pH} 8.0$, and $20 \mathrm{mM}$ $\beta$-mercaptoethanol) and incubated on ice for $10 \mathrm{~min}$. Total nucleic acids were extracted twice with an equal volume of watersaturated phenol-chloroform-isoamylalcohol (25:24:1), followed by extraction with an equal volume of chloroform-isoamylalcohol $(24: 1)$. Extractions were precipitated by the addition of a tenth volume of $10 \mathrm{M} \mathrm{LiCl}$ and an equal volume of 2-propanol and kept on ice for 1 to $2 \mathrm{~h}$, and the precipitate was collected by centrifugation and rinsed with $70 \%$ ethanol. The pellet was dissolved in distilled water and incubated overnight in digestion buffer (30 mM NaOAc, pH 4.6, $5 \mathrm{mM} \mathrm{MgCl}_{2}$, and $1 \mathrm{mM} \mathrm{ZnSO}_{4}$ ) containing 25 units of DNase I (Amersham Biosciences, Piscataway, $\mathrm{NJ}$ ) and 20 units of S1 Nuclease (Takara, Ohtsu, Japan) at $37^{\circ} \mathrm{C}$. The following day, dsRNA was extracted with Tris-EDTA (TE)saturated phenol-chloroform-isoamylalcohol (25:24:1), then extracted with an equal volume of chloroform-isoamylalcohol (24:1) followed by ethanol precipitation, then dissolved in TE. dsRNA was electrophoresed on $1 \%$ agarose gel in Tris-acetate EDTA (TAE) or on 5\% polyacrylamide gel in Tris-borate-EDTA (TBE) buffer and stained with ethidium bromide.

dsRNA detection using RT-PCR. For the synthesis of cDNA, two primer sets, S8-F1 (5'-TAAAGGGAACTGGACTGACG, forward) and S8-R1 (5'-GAAATGGGGTGTCAACGTCC, reverse), and F6 (5'-CTATCAGATCCTTCCGCCAC, forward) and R6 (5'CTGCAAAAGCGTTTGCTACC, reverse), were constructed on the basis of RNA sequence of W370dsRNA segment S8 and S11 (33), respectively. dsRNA extracted as above was diluted to $1 / 100$ with RNase-free water. Diluted dsRNA $(1 \mu \mathrm{l}), 1.38 \mu \mathrm{M}$ each of forward and reverse primers were denatured in $13 \mu \mathrm{l}$ of solution at $95^{\circ} \mathrm{C}$ for $10 \mathrm{~min}$, then quickly cooled on ice. The cDNA was synthesized in $10 \mu \mathrm{l}$ of RT reaction mixture containing $6.5 \mu \mathrm{l}$ of denatured solution, $50 \mathrm{mM}$ Tris- $\mathrm{HCl}(\mathrm{pH} 8.3), 75 \mathrm{mM} \mathrm{KCl}$, $3 \mathrm{mM} \mathrm{MgCl}$, $10 \mathrm{mM}$ dithiothreitol, $1 \mathrm{mM}$ each dNTP, 10 units of RNase inhibitor (TOYOBO, Osaka, Japan), and 10 units of ReverTra Ace (TOYOBO). After incubation at $42^{\circ} \mathrm{C}$ for $1 \mathrm{~h}$, the reaction mixture was heated at $99^{\circ} \mathrm{C}$ for $5 \mathrm{~min}$ to inactivate the reverse transcriptase activity. For PCR amplification of cDNA, two primer sets for nested PCR were constructed: S8-F2 (5'-ACCTCTCTTGCCTCATGACC, forward) and S8-R2 (5'-GAATCGTCGAAACGAGTTGG, reverse), and 6F2 (5'-GTTGTCGAACGAACGAATCG, forward) and 6R2 (5'-CACCTATCGATCAAACGACG, reverse) based on S8 and S11 RNA sequence, respectively. PCR was conducted in $20 \mu \mathrm{l}$ of mixture containing $1 \mu \mathrm{l}$ of cDNA solution, $25 \mathrm{mM} N$-tris(hydroxymethyl)methyl-3-aminopropane sulfonic acid (TAPS), $50 \mathrm{mM} \mathrm{KCl,} 2 \mathrm{~m} \mathrm{M} \mathrm{MgCl} 2,1 \mathrm{mM}$ 2-mercaptoethanol, $0.2 \mathrm{mM}$ each dNTP, and 0.5 units of Ex Taq polymerase (Takara). PCR amplification parameters were as follows: one step at $94^{\circ} \mathrm{C}$ for $2 \mathrm{~min} ; 5$ cycles at $94^{\circ} \mathrm{C}$ for $1 \mathrm{~min}$, $60^{\circ} \mathrm{C}$ for $1 \mathrm{~min}$, and $72^{\circ} \mathrm{C}$ for $1 \mathrm{~min}$; then 25 cycles at $94^{\circ} \mathrm{C}$ for $10 \mathrm{~s}, 60^{\circ} \mathrm{C}$ for $30 \mathrm{~s}$, and $72^{\circ} \mathrm{C}$ for $1 \mathrm{~min}$; and finally one step at $72^{\circ} \mathrm{C}$ for $2 \mathrm{~min}$. The amplification product was analyzed with agarose gel electrophoresis as described above.

Transmission of dsRNAs through hyphal contact. The hygromycin B resistance marker gene was introduced into $R$. necatrix isolates W370T1, W37, W718, and W97 by transformation with plasmid pSH75 to obtain transformed strains RT37-1, RT42, RT45-1, and RT46-2, respectively. All the transformants were confirmed to be dsRNA free by PAGE and grew on PDA containing hygromycin B at $100 \mu \mathrm{g} / \mathrm{ml}$. The inability of wild-type isolates to grow on PDA containing hygromycin B at $50 \mu \mathrm{g} / \mathrm{ml}$ was confirmed. The donor isolate W370 (hygromycin-sensitive) was cultured with a recipient strain at a distance of $4 \mathrm{~cm}$ on a PDA plate $(12 \times 12 \mathrm{~cm})$ at $20^{\circ} \mathrm{C}$ in the dark. After 3 to 12 days of hyphal contact, mycelial plugs $(5 \mathrm{~mm}$ in diameter) were taken from different points in the recipient colony and transferred onto cellophane $(3.1 \times 3.1 \mathrm{~cm})$ overlaid on PDA containing hygromycin $B$ at $100 \mu \mathrm{g} / \mathrm{ml}$ in a 55-mm-diameter petri dishes and incubated at $20^{\circ} \mathrm{C}$ in the dark for 10 days. The cellophane-grown cultures were collected and dsRNA was extracted as described above. Mycelial growth beyond the membrane was transferred to PDA slants and stored at $5^{\circ} \mathrm{C}$.

Virulence assay. Inoculum was prepared following the procedure of Uetake et al. (41) with minor modifications. Isolates and strains were cultured on PDA in thick petri dishes $(2 \mathrm{~cm}$ thick,

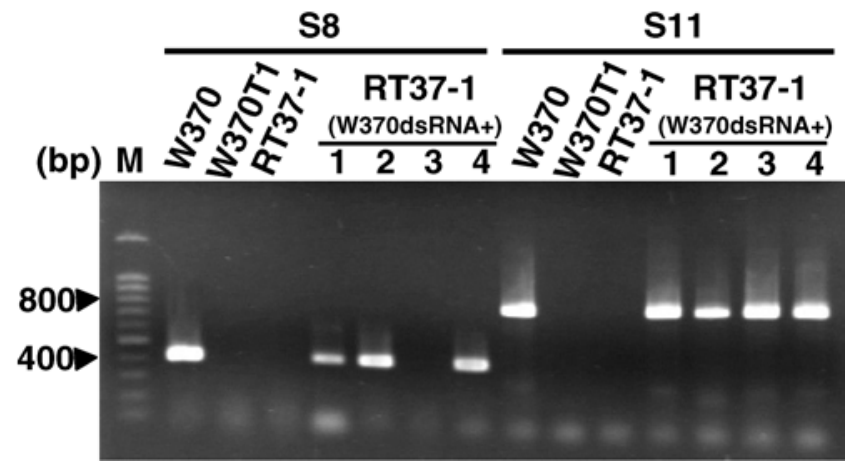

Fig. 2. Reverse-transcription polymerase chain reaction analysis of doublestranded (ds)RNA in Rosellinia necatrix strains. W370: wild-type strain, W370T1: dsRNA-free strain derived from W370 by hyphal tipping, RT37-1: hygromycin B-resistant transformant derived from W370T1, RT371(W370dsRNA+)1 to 4: W370dsRNA-transmitted strains from W370 to RT37-1, RT37-1(W370dsRNA+)3: S8 segment-deficient mutant obtained during subculture. The upper S8 and S11 refer to the dsRNA segment amplified with each specific primer set. 
$9 \mathrm{~cm}$ in diameter) at $20^{\circ} \mathrm{C}$ in the dark for 2 weeks. All inocula were tested for the presence of dsRNA by PAGE prior to use in inoculation tests. Then, 10 to 12 segments of autoclaved apple twigs (1 year old, $25 \mathrm{~mm}$ long, and $8 \mathrm{~mm}$ in diameter) were added to each plate and the plates were incubated for another 3 weeks.

Apple seedlings (Malus pumila var. domestica cv. Golden Delicious) were grown in plastic cups $(13.5 \mathrm{~cm}$ high, $8.5 \mathrm{~cm}$ in upper diameter) containing autoclaved orchard soil and pearlite for $\approx 4$ to 5 months. Roots and soil were carefully pulled out from the cup, two segments of the cultured twigs were placed in contact with the taproot approximately $5 \mathrm{~cm}$ from the bottom of the cup, and the plant and soil were returned to the plastic cup. Inoculated seedlings were kept in a greenhouse at $\approx 25^{\circ} \mathrm{C}$ for 31 days. To check the stability of W370dsRNA in planta, mycelia produced on plants were used directly for dsRNA extraction by carefully collecting mycelial threads formed on the infected roots with forceps and put in a microcentrifuge tube after the 31-day incubation period. In order to eliminate small soil particles from the collected mycelial threads, they were washed once with $0.05 \%$ Tween 80 by finger vortexing for $30 \mathrm{~s}$, followed by two additional washes with distilled water. dsRNA was extracted from each sample as described above for cellophane-grown cultures and the presence of dsRNA was checked with PAGE analysis.

Mycelial growth. The effect of W370dsRNA on mycelial growth was tested on PDA or Czapek-Dox agar (Difco Laboratories) at $20^{\circ} \mathrm{C}$ in the dark and on apple twigs buried in the soil. A piece of twig inoculum prepared as above was tied to a living, dormant apple twig (10 cm long, $8 \mathrm{~mm}$ in diameter) and incubated in a culture tube $(11.5 \mathrm{~cm}$ high, $2.5 \mathrm{~cm}$ in diameter) containing soil (horticulture potting compost; Kureha Chemical Industry, Tokyo) at $25^{\circ} \mathrm{C}$ in the dark. After 8 days, twigs were carefully retrieved from the soil and the length of the mycelia grown on apple twigs from the inoculum was measured.

\section{RESULTS}

Protoplast production and transformation. Each culture yielded a total of 1 to $2.5 \times 10^{7}$ protoplasts $\left(0.5\right.$ to $1 \times 10^{7}$ protoplasts per $\mathrm{g}$ of wet mycelia) with a 0.01 to $0.03 \%$ regeneration frequency after transfer to the nonselective regeneration medium. Protoplasts from a single batch were used in two transformation tests. With the optimized transformation protocol described above, the transformation frequencies of $R$. necatrix with plasmids pSH75 and pAN7.1 averaged 2 and 5 transformants per $10 \mu \mathrm{g}$ of DNA, respectively. Southern analysis revealed that each transformant contained one to several copies of the $h p h$ gene

TABLE 1. Transmission of W370dsRNA through hyphal contact

\begin{tabular}{llcc}
\hline & Strain $^{\mathrm{a}}$ & & \\
\cline { 1 - 2 } Donor & Recipient (origin) & Plate no. & With dsRNA/total ${ }^{\mathrm{b}}$ \\
\hline W370 & RT37-1 (W370T1) & 1 & $5 / 17$ \\
& & 2 & $6 / 17$ \\
W370 & RT4-2 (W37) & 3 & $6 / 17$ \\
W370 & RT45-1 (W97) & 1 & $0 / 7$ \\
& & 1 & $0 / 6$ \\
W370 & RT46-2 (W718) & 2 & $0 / 6$ \\
& & 1 & $0 / 6$ \\
& & 2 & $0 / 6$ \\
\hline
\end{tabular}

${ }^{a}$ The donor isolate and a hygromycin-resistant recipient strain were inoculated on potato dextrose agar (PDA) plates at $20^{\circ} \mathrm{C}$ in the dark. Mycelial plugs were taken from different points in the recipient colony and subcultured on PDA containing hygromycin B at $100 \mu \mathrm{g} / \mathrm{ml}$ to select subcultures for double-stranded (ds)RNA testing.

${ }^{b}$ Number of subcultures with dsRNA per number of total subcultures. The presence of dsRNA was determined by polyacrylamide-gel electrophoresis.

c Vegetatively incompatible with W370. integrated in their genome DNA (data not shown). The transformation protocol proved to be useful for all four $R$. necatrix isolates tested.

The optimal conditions for protoplast preparation and regeneration outlined above were selected while evaluating a number of conditions (data not shown), including culture of mycelia with none or gentle shaking; mannitol or sorbitol osmotica at 0.5 to $1.2 \mathrm{M}$ or $\mathrm{NaCl}$ at $0.7 \mathrm{M}$; lytic enzymes $1 \%$ Zymolyase 20T, $0.4 \%$ Zymolyase 100T, 1\% Lysing enzyme, and $0.25 \%$ Kitalase (Wako); incubation temperature of 20 to $30^{\circ} \mathrm{C}$ for 1 to $3 \mathrm{~h}$ in one of the following $10 \mathrm{mM}$ buffers (Maleic acid, pH 5.6; 2-morpholinoethanesulfonic acid [MES], $\mathrm{pH}$ 6.0; MOPS, $\mathrm{pH}$ 7.0; or Tris$\mathrm{HCl}, \mathrm{pH}$ 7.0); PDB regeneration broth amended with $0.5 \mathrm{M}$ glucose or MMC buffer; and solid regeneration media YCDA or PDA amended with $0.5 \mathrm{M}$ glucose.

Likewise, the optimal transformation conditions given above were selected after comparison of the following conditions (data not shown): PEG treatment of 0.5 or $1 \mathrm{ml}$ of 40 or $60 \%$ PEG 4000 , regeneration following transformation by washing the transformed protoplasts by centrifugation or direct dilution with regeneration broth, followed by incubation for 0 to 7 days prior to plating on regeneration solid medium.

Curing and transmission of W370dsRNAs. All of the 23 hyphal-tip strains generated from W370 contained no detectable dsRNA segments on PAGE (data not shown). A representative hyphal-tip strain, W370T1, was transformed with the $h p h$ gene and the resultant transformant, RT37-1, was used for dsRNA transmission tests. W370dsRNA were transmitted in an all or none fashion from isolate W370 to RT37-1 in dual culture and each transmitted dsRNA segment was in an equimolar ratio (Fig. 1A). dsRNAs in the recipient strain RT37-1 were restricted to the area near the colony junction and the growing mycelia, newly developed after hyphal contact. Transmission of W370dsRNA from W370 to vegetatively incompatible isolates RT4-2, RT45-1, and RT46-2 was not observed by PAGE (Table 1) and RT-PCR analysis (data not shown).

Effect of W370dsRNA on colony morphology and mycelial growth. Four strains were selected randomly from transmission tests (Table 1): RT37-1(W370dsRNA+)1 to 4, to investigate the effect of W370dsRNA on $R$. necatrix. RT37-1(W370dsRNA+)1, 2 , and 4 contained approximately equimolar amounts of the 12 dsRNA segments, as did the donor isolate, W370, on PAGE (Fig. 1A). However, RT37-1(W370dsRNA+)3 lost the S8 dsRNA segment during subculture (Figs. 1A and 2), and remained stable after more than 10 subcultures. Small remnants of the S8 dsRNA were not detected in strain RT37-1(W370dsRNA+)3 by PAGE analysis, even when 10-fold samples were electrophoresed on $10 \%$ PAGE (data not shown).

The colony morphology of W370dsRNA-containing strains (W370, RT37-1(W370dsRNA+)1 to 4) appeared amorphous with dense mycelia compared with dsRNA-free strains W370T1 and RT37-1 (Fig. 1B). However, the difference was not as clear after mycelia extended to the edge of plates.

The mycelial growth rate of parent strain RT37-1 and W370dsRNA-transmitted strains RT37-1(W370dsRNA+)1 to 4 were compared under different conditions. Strains RT371(W370dsRNA+)1 to 4 showed reduced mycelial growth on PDA (Figs. 1B and 3A), Czapek-Dox agar (Fig. 3B) and apple twigs buried in the soil (Figs. 3C and 4) compared with the dsRNAfree, parental strain RT37-1. For example, mycelial growth on apple twigs buried in the soil was reduced by 50 to $70 \%$ after transmission with W370dsRNA (Fig. 3C).

To assess the effect of dsRNA curing on these isolates, five hyphal-tip cultures were prepared from strains RT371 (W370dsRNA+) 1 to 4 . It was confirmed that all 20 cultures were dsRNA free by PAGE analysis and strains were restored to the phenotype of the parent strain (RT37-1) for growth rate and colony morphology on PDA (data not shown). 
Hypovirulence of W370dsRNA. dsRNA-free strains W370T1 and its transformant RT37-1 caused wilt symptoms and killed apple seedlings more extensively than did the W370dsRNA-containing strains W370 and RT37-1(W370dsRNA+)1 to 4 (Fig. 5; Table 2). After the incubation period, seedlings were taken out of the pot and their roots were observed for mycelial development. Mycelia were found to have developed up to the stem base (top of the taproot) in killed seedlings, but were restricted to around the point of inoculation or disappeared in living seedlings. Some apple seedlings were killed in 31 days after inoculation with strains containing W370dsRNA (i.e., W370 in experiments 1 and 2, and RT37-1(W370dsRNA+) 1 in experiments 1, 2, and 3) (Table 2). Mycelia collected from the root surfaces of these killed seedlings did not contain dsRNA according to PAGE with only one exception: in experiment 3, a mycelial sample of RT371(W370dsRNA+) 1 contained dsRNA even though the seedling died. In contrast, mycelia collected from roots of healthy seedlings contained W370dsRNA (data not shown).

\section{DISCUSSION}

The presence of hypovirulence in $R$. necatrix was demonstrated by hyphal-tip isolation and transmission tests with a fungal virus that contained 12 segments of dsRNA. A representative dsRNAfree strain was obtained by hyphal tipping the dsRNA-containing wild-type isolate and confirmed to be dsRNA free by PAGE and RT-PCR analysis. In order to investigate transmission of the dsRNA on $R$. necatrix without possible contamination of donor mycelia in the recipient colony, an antibiotic-resistant transformant of the dsRNA-free strain was developed. In hyphal anastomosis transmission studies, the dsRNA was transmitted to the recipient strain, though its spread was restricted to the contact area between the two cultures. The use of antibiotic-resistant transformants confirmed the all-or-none fashion for transmission of the dsRNA segments. Loss of the dsRNA through hyphal tipping resulted in a faster mycelial growth rate, whereas its acquisition through dual culture restored the wild-type dsRNAcontaining phenotype. Moreover, the dsRNA-transmitted strains showed faster mycelial growth after hyphal tipping, which made the strains dsRNA free. The weakly virulent, wild-type strain containing dsRNA became more virulent after dsRNA curing by hyphal tipping, and its antibiotic-resistant transformant became hypovirulent after obtaining the dsRNA in dual culture. These results provide clear evidence that the W370dsRNA confers hypovirulence to $R$. necatrix. Hypovirulence of $R$. necatrix also was correlated with reduced mycelial growth on apple twigs buried in soil, which represents conditions more similar to what the pathogen encounters in planta than in plate culture.

Interest in virulence-attenuating mycoviruses has been stimulated by several reports on plant-pathogenic fungi, such as Ophiostoma ulmi (37), Diaporthe ambigua (39), Sclerotinia spp. (7,26, 44), Rhizoctonia solani (9), Fusarium graminearum (11), and Leucostoma persoonii (16), in addition to extensive studies on C. parasitica $(12,17)$. Similar to these systems, the W370dsRNA virus has potential as a biocontrol agent for white root rot caused by $R$. necatrix.

In order to utilize dsRNA as a biocontrol agent, it must be stable and efficiently spread in fungal populations (25). The stability of W370dsRNA in planta was determined by detecting the dsRNA directly from mycelial threads growing on roots in the soil. Preliminary attempts to detect the dsRNA using cultures established from re-isolations from roots were not successful, presumably because the re-isolation process was similar to hyphal tipping and, consequently, many of the subcultures turned out to be dsRNA free, even when the dsRNA was present in the isolates in planta. The W370dsRNA in strains RT37-1(W370dsRNA+)2 to 4 were stable throughout the inoculation experiments with plants; however, W370 and RT37-1(W370dsRNA+)1 occasion- ally became dsRNA free. Therefore, it was assumed that the W370dsRNA in W370 and RT37-1(W370dsRNA+)1 had disappeared during inoculation in some pots. dsRNA-free sectors may have occurred and predominated over the dsRNA-containing strains on the infected apple root, as was sometimes observed in plate cultures, resulting in the failure to detect dsRNA from inoculated plants. If the reason for the difference in W370dsRNA stability among strains is clarified, it should help facilitate the development of W370dsRNA as a biocontrol agent.

$R$. necatrix propagates mainly through mycelial spread in the soil, with ascospores rarely observed in orchards $(28,34)$, and conidia do not develop into mycelia (28). Consequently, the risk of virus-curing during sporulation is unlikely. In this regard, the $R$. necatrix-W370 virus system differs from $C$. parasitica $(3,14$, 27), O. ulmi (37), and F. graminearum (11). One potential problem with implementing the W370dsRNA for biological control is the lack of effective spread throughout the mycelia of recipient strains. Its spread was limited to the hyphae growing out from zones of contact and might be blocked from movement to older parts of the colony by the death of fused cells, even with parings between vegetatively compatible isolates (1). Additional work currently is in progress evaluating additional dsRNAs from other isolates of $R$. necatrix for hypovirulence and improved distribution in recipient strains.

The use of a fungal virus for biological control largely depends on the population structure of the pathogens, because diversity in
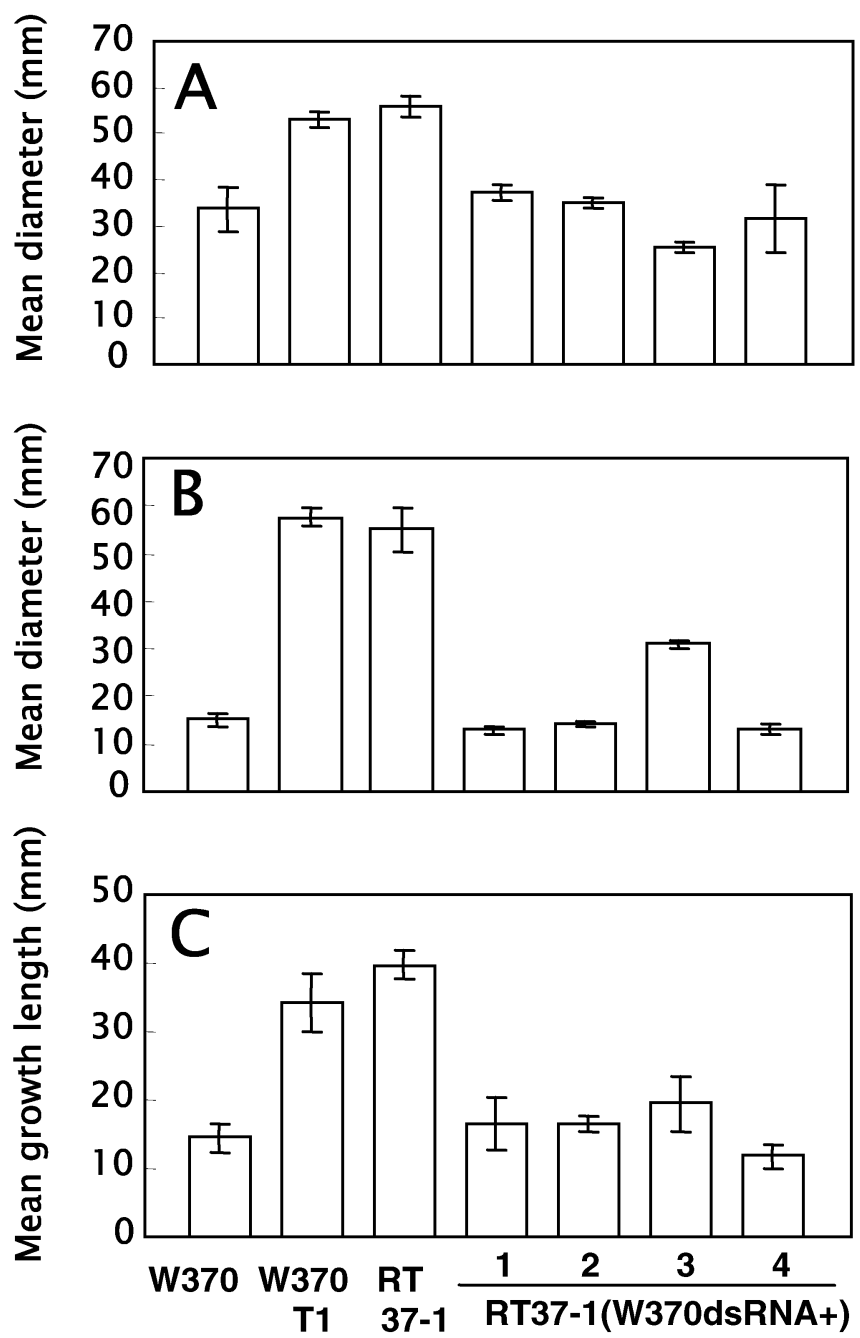

Fig. 3. Mycelial growth on A, potato dextrose agar, B, Czapek-Dox agar, and C, apple twig in soil at 20,20 , and $25^{\circ} \mathrm{C}$ after 6,12 , and 8 days of incubation, respectively. Each bar represents the average from $\mathbf{A}$ and $\mathbf{B}$, six or $\mathbf{C}$, five different cultures of each strain with standard deviations. 
vegetative incompatibility may hinder the effort to introduce and disseminate the fungal virus (17). In this experiment, the W370dsRNA was transmitted only between vegetatively compatible isolates, as has been observed with the hypovirus in $C$. parasitica (17). Vegetative compatibility groups, determined by the formation of dark demarcation lines between colonies on solid media, varied among the populations of $R$. necatrix on avocado in Southern Spain: $24 \%$ of the isolates from the same orchard were compatible, whereas isolates from different orchards were all incompatible (34). Similar results were obtained from orchards planted with Japanese pear and loquat in Japan; vegetatively compatible isolates often were found to colonize more than 10 trees in a patch, and, as a rule, isolates from the same tree also demonstrated vegetative compatibility (H. Nakamura, unpublished data). Although bridging isolates capable of anastomosis between vegetatively compatible groups have not been identified in $R$. necatrix, Aimi et al. (2) observed hyphal anastomosis between an isolate of $R$. necatrix and other isolates differing in vegetative compatibility under the microscope. If these isolates can transmit W370dsRNA through such contacts, the prospects for using this dsRNA as a biocontrol agent may be improved.

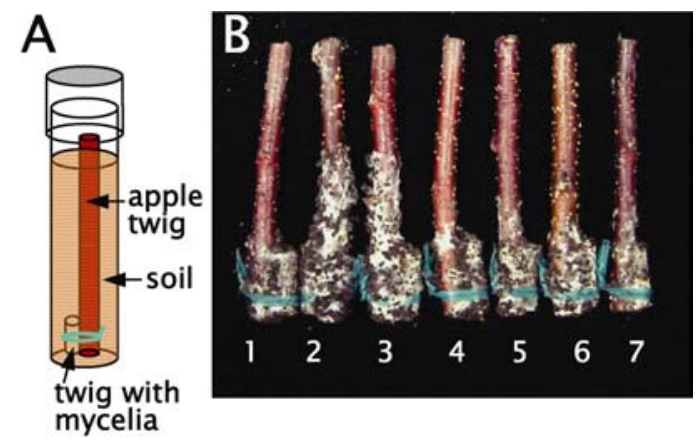

Fig. 4. Mycelial growth on apple twigs buried in the soil. A, Diagram of the method further described in the text; B, mycelial growth of double-stranded (ds)RNA-free and dsRNA-containing strains (1: W370, 2: W370T1, 3: RT371, 4 to 7: RT37-1(W370dsRNA+)1 to 4) of Rosellinia necatrix on apple twig at $25^{\circ} \mathrm{C}$ after 8 days of incubation.
The specific effects of the W370dsRNA on $R$. necatrix are unknown but its presence reduced mycelial growth on apple twigs buried in the soil and on culture media, which correlated with reduced virulence on apple seedlings. Though $R$. necatrix is known to produce toxic metabolites, such as cytochalasin E (19), the mechanism of pathogenesis on fruit trees remains unclear. Hypovirus infection in $C$. parasitica caused numerous genes to be upor downregulated (31); it is possible that a similar scenario may be occurring in hypovirulent isolates of $R$. necatrix as well.

The genome segment S8 disappeared from one dsRNA-containing strain during subculture. This S8-deficient strain (RT371(W370dsRNA+)3) exhibited hypovirulence (Fig. 5; Table 2) and its dsRNA was transmitted to dsRNA-free strains (RT37-1 and W370T1) the same way as the wild-type W370dsRNA (data not shown). The deduced amino-acid sequence from the S8 segment revealed no clear similarity to those from other viruses previously reported (33). There are other examples where dsRNA viruses have lost a genome segment. In the case of species of Phytoreovirus, transmission-defective (TD) strains via insect vector were obtained after vegetative propagation in plant hosts for several years without vector transmission, and these strains lost the P2

TABLE 2. Virulence of W370dsRNA-containing and -free strains on apple seedlings

\begin{tabular}{lccc}
\hline & \multicolumn{3}{c}{ Seedlings: no. killed/no. inoculated } \\
\cline { 2 - 4 } Strain & Exp. 1 & Exp. 2 & Exp. 3 \\
\hline W370 & $3^{\mathrm{b} / 6}$ & $1^{\mathrm{b} / 5}$ & $0 / 6$ \\
W370T1 & $6 / 6$ & $3 / 5$ & $3 / 6$ \\
RT37-1 & $6 / 6$ & $5 / 5$ & $4 / 6$ \\
RT37-1(W370dsRNA+) 1 & $6^{\mathrm{b} / 6}$ & $1^{\mathrm{b} / 5}$ & $1 / 6$ \\
RT37-1(W370dsRNA+) 2 & $0 / 6$ & $0 / 5$ & $0 / 6$ \\
RT37-1(W370dsRNA+) 3 & $0 / 6$ & $0 / 5$ & $0 / 6$ \\
RT37-1(W370dsRNA+) 4 & $0 / 6$ & $0 / 5$ & $0 / 6$ \\
Control $^{\mathrm{c}}$ & $0 / 6$ & $0 / 5$ & $0 / 6$ \\
\hline
\end{tabular}

a Seedlings 4 to 5 months old received inoculum of the respective strains and were incubated in a greenhouse at $\approx 25^{\circ} \mathrm{C}$. The number of killed seedlings was counted 31 days after inoculation.

${ }^{\mathrm{b}}$ W370dsRNA was not detected in the pathogen mycelia growing on killed seedlings.

${ }^{c}$ Not inoculated.

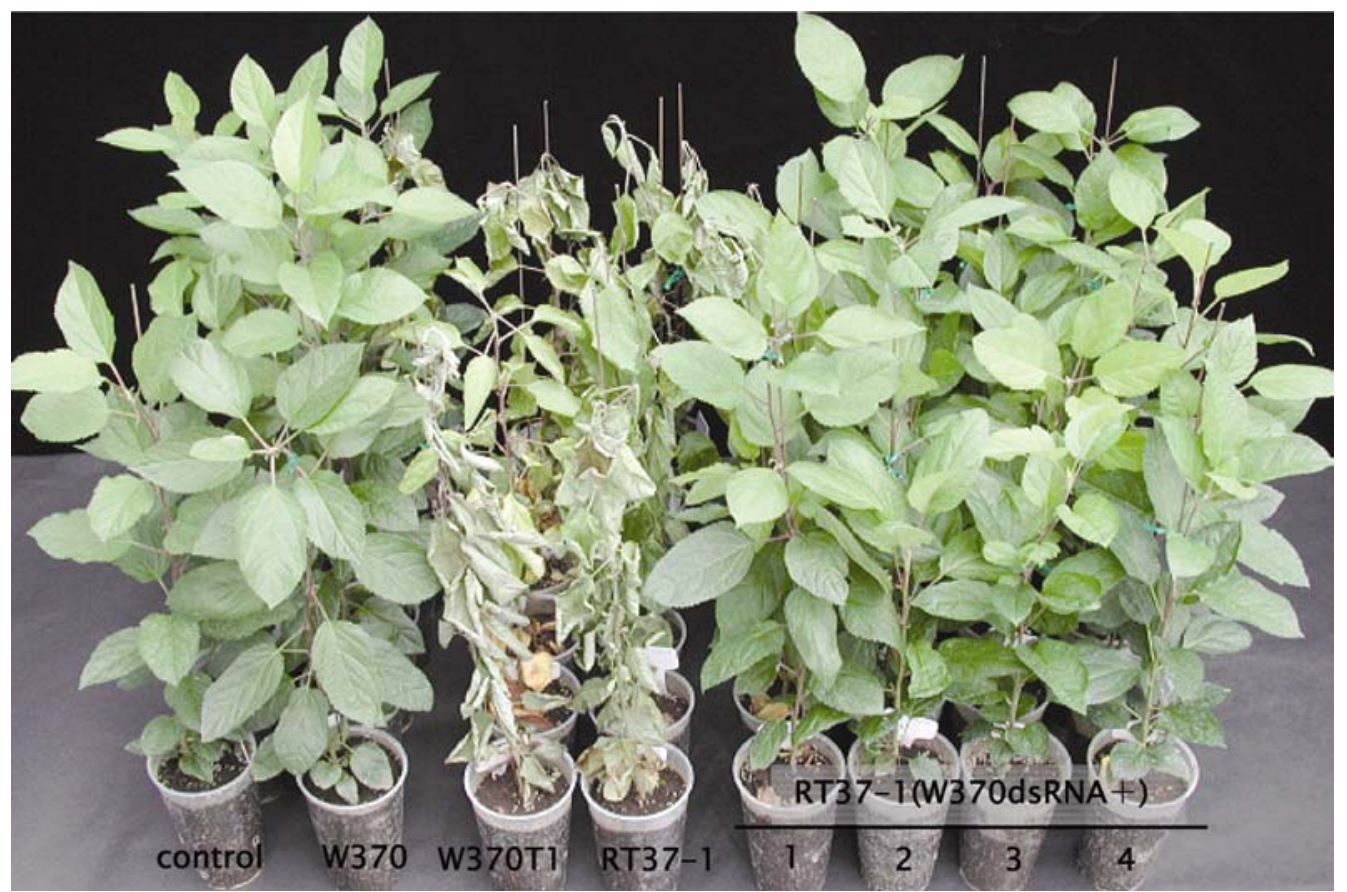

Fig. 5. Virulence on apple seedlings 13 days after inoculation. Isolate W370 and strains RT37-1(W370dsRNA+)1 to 4 had W370dsRNA, and strains W370T1 and RT37-1 were dsRNA-free. 
protein which encoded on the segment S2 in Rice dwarf virus (RDV) $(21,32)$. Similarly, a genome segment S2 or S5 was missing in Wound tumor virus (WTV) TD strains $(30,36)$, and a Rice ragged stunt virus (RRSV) TD strain reduced the amount of genome segment S10 (23). In view of the stability of the other dsRNA segments in the S8-deficient strain maintained in culture, the putative protein encoded on the S8 segment of 370dsRNA is not essential for viral proliferation or transmission in $R$. necatrix.

Segment-deficient mutants previously reported in WTV (36), RRSV (23), Avian reovirus (29), and Mammalian reovirus (45) were deletion mutants of a segment and bore genome remnants; that is to say, small dsRNA fragments. The genome remnants (more than $300 \mathrm{bp}$ ) are derived from linear genomes and have been characterized by the conserved termini on both ends of the segment $(4,45)$. Both terminal sequences in the small remnants are considered to be important for packaging of the segment $(4,45)$. However, small remnants were not detected in the dsRNA contained in the S8-deficient strain (RT37-1(W370dsRNA+)3) in this experiment, suggesting the complete loss of the S8 segment or the generation of minor remnants too small to detect (probably less than $100 \mathrm{bp}$ ). This S8-deficient mutant may provide new insights into packaging mechanism of viruses in the family Reoviridae.

DNA-mediated transformation techniques have been applied for several fungi to introduce marker genes and analyze gene function. Because of the difficulty in protoplast preparation in $R$. necatrix, due primarily to low rates of protoplast formation with lytic enzymes and slow regeneration of protoplasts, the transformation efficiency was relatively low. However, the transformation protocol reported here has been optimized for $R$. necatrix and was useful for obtaining transformants with newly introduced genes. Because the protoplast-mediated technique provides an alternative method for viral infection, this method will be particularly useful for introducing hypovirulence factors to field isolates with different vegetative compatibility. Field isolates with hypovirulence then may be used as inoculum to cure fruit trees infected with $R$. necatrix.

Further research is needed to overcome some of the limitations of using W370dsRNA as a biocontrol agent. For example, the stability of the virus in the mycelium and the speed by which it spreads throughout a population in the field needs to be examined, as does the influence of diversity of vegetative compatibility groups on limiting transmission of the dsRNA among isolates in a population. Nevertheless, the intriguing properties of W370dsRNA described here should facilitate future studies to control $R$. necatrix and also contribute to fungal virology.

\section{ACKNOWLEDGMENTS}

This research was supported by the program for Promotion of Basic Research Activities for Innovative Biosciences. S. Kanematsu received financial assistance in the form of a fellowship under the OECD cooperative research program Biological Resource Management for Sustainable Agriculture Systems. We thank T. Tsuge and R. Oliver for providing plasmids, and B. I. Hillman for presubmission review. Contribution no. 1332 of the National Institute of Fruit Tree Science, NARO.

\section{LITERATURE CITED}

1. Aimi, T., Kano, S., Yotsutani, Y., and Morinaga, T. 2002. Telomeric fingerprinting of the white root rot fungus, Rosellinia necatrix: A useful tool for strain identification. FEMS Microbiol. Lett. 217:95-101.

2. Aimi, T., Yotsutani, Y., and Morinaga, T. 2002. Vegetative incompatibility in the ascomycete Rosellinia necatrix studied by fluorescent microscopy. J. Basic Microbiol. 42:147-155.

3. Anagnostakis, S. L. 1983. Biological control of chestnut blight. Science 215:466-471.

4. Anzola, J. V., Xu, Z., Asamizu, T., and Nuss, D. 1987. Segment-specific inverted repeats found adjacent to conserved terminal sequences in wound tumor virus genome and defective interfering RNAs. Proc. Natl. Acad. Sci. USA 84:8301-8305.
5. Arakawa, M., Nakamura, H., Uetake, Y., and Matsumoto, N. 2002. Presence and distribution of double-stranded RNA elements in the white root rot fungus Rosellinia necatrix. Mycoscience 43:21-26.

6. Araki, T. 1967. Soil condition and the violet and white root rot diseases of fruit trees. Bull. Natl. Agric. Sci. C21:1-110.

7. Boland, G. 1992. Hypovirulence and double-stranded RNA in Sclerotinia sclerotiorum. Can. J. Plant Pathol. 14:10-17.

8. Buck, K. W. 1998. Molecular variability of viruses of fungi. Pages 53-72 in: Molecular Variability of Fungal Pathogens. CAB International, Wallingford, UK.

9. Castanho, B., and Butler, E. E. 1978. Rhizoctonia decline: Studies on hypovirulence and potential use in biological control. Phytopathology 68:1511-1514.

10. Choi, G. H., Larson, T. G., and Nuss, D. L. 1992. Molecular analysis of the laccase gene from the chestnut blight fungus and selective suppression of its expression in an isogenic hypovirulent strain. Mol. PlantMicrobe Interact. 5:119-128.

11. Chu, Y. M., Jeon, J. J., Yea, S. J., Kim, Y. H., Yun, S. H., Lee, Y. W., and Kim, K. H. 2002. Double-stranded RNA mycovirus from Fusarium graminearum. Appl. Environ. Microbiol. 68:2529-2534.

12. Dawe, A. L., and Nuss, D. L. 2001. Hypoviruses and chestnut blight: Exploiting viruses to understand and modulate fungal pathogenesis. Ann. Rev. Genet. 35:1-29.

13. Enebak, S. A., Hillman, B. I., and MacDonald, W. L. 1994. A hypovirulent isolate of Cryphonectria parasitica with multiple, genetically unique dsRNA segments. Mol. Plant-Microbe Interact. 7:590-595.

14. Enebak, S. A., MacDonald, W. L., and Hillman, B. I. 1994. Effect of dsRNA associated with isolates of Cryphonectria parasitica from the central Appalachians and their relatedness to the dsRNAs from north America and Europe. Phytopathology 84:528-534.

15. Ghabrial, S. A. 1998. Origin, adaptation and evolutionary pathways of fungal viruses. Virus Genes 16:119-131.

16. Hammar, S., and Fulbright, D. W. 1989. Association of double-stranded RNA with low virulence in an isolate of Leucostoma persoonii. Phytopathology 79:568-572.

17. Heiniger, U., and Rigling, D. 1994. Biological control of chestnut blight in Europe. Annu. Rev. Phytopathol. 32:581-599.

18. Kanadani, G., Date, H., and Nasu, H. 1998. Effect of Fluazinam soildrench on white root rot of grapevine. Ann. Phytopathol. Soc. Jpn. 64:139-141.

19. Kanematsu, S., Hayashi, T., and Kudo, A. 1997. Isolation of Rosellinia necatrix mutants with impaired cytochalasin E production and its pathogenicity. Ann. Phytopathol. Soc. Jpn. 62:425-431.

20. Khan, A. H. 1959. Biology and pathogenicity of Rosellinia necatrix (Harti.) Berl. Biologia 5:199-245.

21. Kimura, I. 1976. Loss of vector-transmissibility in an isolate of rice dwarf virus. Ann. Phytopathol. Soc. Jpn. 42:322-324.

22. Kimura, N., and Tsuge, T. 1993. Gene cluster involved in melanin biosynthesis of the filamentous fungus Alternaria alternata. J. Bacteriol. 175:4427-4435.

23. Maoka, T., Omura, T., Harjosudarmo, J., Usugi, T., Hibino, H., and Tsuchizaki, T. 1993. Loss of vector-transmissibility by maintaining rice ragged stunt virus in rice plants without vector transmission. Ann. Phytopathol. Soc. Jpn. 59:185-187.

24. Matsumoto, N. 1998. Biological control of root diseases with dsRNA based on population structure of pathogens. JARQ 32:31-35.

25. McCabe, P. M., Pfeiffer, P., and van Alfen, N. K. 1999. The influence of dsRNA viruses on the biology of plant pathogenic fungi. Trends Microbiol. 7:377-381.

26. Melzer, M. S., and Boland, G. J. 1996. Transmissible hypovirulence in Sclerotinia minor. Can. J. Plant Pathol. 18:19-28.

27. Melzer, M. S., Dunn, M., Zhou, T., and Boland, G. J. 1997. Assessment of hypovirulent isolates of Cryphonectria parasitica for potential in biological control of chestnut blight. Can. J. Plant Pathol. 19:69-77.

28. Nakamura, H., Uetake, Y., Arakawa, M., Okabe, I., and Matsumoto, N. 2000. Observations the teleomorph of the white root rot fungus, Rosellinia necatrix, and a related fungus, Rosellinia aquila. Mycoscience 41:503-507.

29. Ni, Y., and Kemp, M. C. 1994. Subgenomic S1 segments are packaged by avian reovirus defective interfering particles having an $\mathrm{S} 1$ segment deletion. Virus Res. 32:329-342.

30. Nuss, D. L. 1984. Molecular biology of wound tumor virus. Adv. Virus Res. 29:57-93.

31. Nuss, D. L. 1996. Using hypoviruses to probe and perturb signal transduction processes underlying fungal pathogenesis. Plant Cell 8:18451853.

32. Omura, T., and Yan, J. 1999. Role of outer capsid proteins in transmission of Phytoreovirus by insect vectors. Adv. Virus Res. 54:15-43.

33. Osaki, H., Wei, C. Z., Arakawa, M., Iwanami, T., Nomura, K., Matsumoto, N., and Ohtsu, Y. 2002. Nucleotide sequences of double- 
stranded RNA segments from a hypovirulent strain of the white root rot fungus Rosellinia necatrix: Possibility of the first member of the Reoviridae from fungus. Virus Genes 25:101-108.

34. Pérez Jiménez, R. M., Jiménez Díaz, R. M., and Lopéz Herrera, C. J. 2002. Somatic incompatibility of Rosellinia necatrix on avocado plants in southern Spain. Mycol. Res. 106:239-244.

35. Punt, P. J., Oliver, R. P., Dingemanse, M. A., Pouwels, P. H., and Hondel, C. A. M. J. J. 1987. Transformation of Aspergillus based on the hygromycin B resistance marker from Escherichia coli. Gene 56:117-124.

36. Reddy, D. V. R., and Black, L. M. 1974. Deletion mutations of the genome segments of wound tumor virus. Virology 61:458-473.

37. Rogers, H. J., Buck, K. W., and Braiser, C. M. 1986. Transmission of double-stranded RNA and a disease factor in Ophiostoma ulmi. Plant Pathol. 35:277-287.

38. Sambrook, J., Fritsch, E. F., and Maniatis, T. 1989. Molecular Cloning: A Laboratory Manual. Cold Spring Harbor Laboratory, Cold Spring Harbor, NY.

39. Smit, W. A., Wingfield, B. D., and Wingfield, M. J. 1996. Reduction of laccase activity and other hypovirulence-associated traits in dsRNAcontaining strains of Diaporthe ambigua. Phytopathology 86:1311-1316.
40. Sztejnberg, A., and Madar, Z. 1980. Host range of Dematophora necatrix, the cause of white root rot disease in fruit trees. Plant Dis. 64:662-664.

41. Uetake, Y., Nakamura, H., Arakawa, M., Okabe, I., and Matsumoto, N. 2001. Inoculation of Lupinus luteus with white root rot fungus, Rosellinia necatrix, to estimate virulence. J. Gen. Plant Pathol. 67:285-287.

42. van Regenmortel, M. H. V., Fauquet, C. M., Bishop, D. H. L., Carstens, E. B., Estes, M. K., Lemon, S. M., Maniloff, J., Mayo, M. A., McGeoch, D. J., Pringle, C. R., and Wickner, R. B. 2000. Virus Taxonomy, Classification and Nomenclature of Viruses: Seventh Report of the International Committee on Taxonomy of Viruses. Academic Press, San Diego, CA.

43. Wei, C. Z., Osaki, H., Iwanami, T., Matsumoto, N., and Ohtsu, Y. 2003. Molecular characterization of dsRNA segments 2 and 5 and electron microscopy of a novel reovirus from a hypovirulent isolate, W370, of the plant pathogen Rosellinia necatrix. J. Gen. Virol. 84:2431-2437.

44. Zhou, T., and Boland, G. J. 1997. Hypovirulence and double-stranded RNA in Sclerotinia homoeocarpa. Phytopathology 87:147-153.

45. Zou, S., and Brown, E. G. 1992. Identification of sequence elements containing signals for replication and encapsidation of the Reovirus M1 genome segment. Virology 186:377-388. 